\title{
Microstructural Characterization and Mechanical Properties of Fiber Laser Welded CP-Ti and Ti-6Al-4V Similar and Dissimilar Joints
}

\author{
Alireza Abdollahi *D, Ahmed Shaheer Ahnaf Huda and Abu Syed Kabir \\ Department of Mechanical and Aerospace Engineering, Carleton University, Ottawa, ON K1S 5B6, Canada; \\ AhmedShaheerAhnafHud@cmail.carleton.ca (A.S.A.H.); abu.kabir@carleton.ca (A.S.K.) \\ * Correspondence: alirezaabdollahi@cmail.carleton.ca; Tel.: +1-613-520-2600
}

Received: 4 May 2020; Accepted: 30 May 2020; Published: 3 June 2020

check for updates

\begin{abstract}
In this research, the microstructures and mechanical properties of similar and dissimilar autogenous joints of $3 \mathrm{~mm}$ thick commercially pure titanium (CP-Ti) and Ti-6Al-4V welded by ytterbium fiber laser (Yb:YAG) were investigated. Two sets of laser power and welding speed were selected in such a way that the heat input remained constant. Microstructural characterization of the joints was investigated by an optical microscope, and mechanical properties were determined by hardness and tensile tests. The only defects found were porosity and underfill, and no signs of lack of penetration and solidification cracks were observed in any of the joints. Microstructural evaluation of the fusion zone (FZ) showed that in similar Ti-6Al-4V joint, a supersaturated nonequilibrium $\alpha^{\prime}$ martensite was formed due to rapid cooling associated with laser welding. In similar CP-Ti, coarse equiaxed grains were observed in the FZ. Unlike the similar joints, a clear interface was observed between the heat-affected zone (HAZ) and the FZ in both the CP-Ti and Ti-6Al-4V sides in dissimilar joints. Among all the joints with different weld parameters, similar Ti-6Al-4V showed the highest strength and the lowest ductility. In similar $\mathrm{CP}-\mathrm{Ti}$ and dissimilar joints, fractures took place in the CP-Ti base metal, but all the Ti-6Al-4V similar joints failed in the FZ. Significant changes in the strength and hardness with varying laser power and welding speed implied that the mechanical properties of the weld fusion zones were not entirely governed by the heat input but were also affected by individual welding parameters.
\end{abstract}

Keywords: dissimilar welding; CP-Ti; Ti-6Al-4V; ytterbium fiber laser

\section{Introduction}

In the past few decades, titanium alloys have gained considerable popularity in several engineering industries due to their remarkable strength-to-weight ratio [1]. Titanium alloys are typically five types depending on the alloying elements present, namely, alpha $(\alpha)$ alloys, near-alpha alloys, alpha-beta $(\beta)$ alloys, beta alloys, and near-beta alloys. A wide range of mechanical properties portrayed by these five types of titanium alloys has allowed industries to adopt the best one that suits their purpose [2]. The good formability, toughness, and corrosion resistance of commercially pure titanium (CP-Ti), an $\alpha$ alloy, have paved the way for this alloy to be used in aerospace applications, including floor support structure in the galley and lavatory areas, tubes or pipes in the lavatory system, clips and brackets, and ducting for the anti-icing and environmental control systems [2,3]. Ti-6Al-4V (Ti-64), an $\alpha-\beta$ alloy, has a high strength-to-weight ratio and excellent corrosion resistance, which make it the most versatile titanium alloy in the aerospace industry. Some of the uses include the static and rotating components of gas turbine engines, fuselage, nacelles, and landing gear [4].

The microstructure of CP-Ti does not vary too much with heat treatment, especially with low to moderate cooling rate from above the $\beta$-transus temperature [5]. At a high cooling rate, the formation 
of twins has been reported in the microstructure, which also moderately increases the strength [6]. The equilibrium microstructure of Ti-64 at room temperature consists of retained $\beta$-phase within the $\alpha$ matrix [7]. The transformation of the $\beta$-phase from or above the $\beta$-transus temperature $\left(\sim 995^{\circ} \mathrm{C}\right)$ is linked to the cooling rate. At a relatively slow cooling rate, the $\beta$-phase transforms to the $\alpha$-phase. Increasing cooling rate affects not only the nucleation rate of $\alpha$ at the $\beta$ grain boundaries but also the length and width of $\alpha$ platelets [8]. At a very high cooling rate (quenching), the $\beta$-phase fully or partially transforms into martensitic $\alpha$, named as $\alpha^{\prime}$. Ahmed and Rack [9] reported that $410^{\circ} \mathrm{C} / \mathrm{s}$ is the minimum cooling rate necessary for a full martensite structure for Ti-64. In this alloy, due to the presence of enough $\beta$-phase stabilizer element ( $4 \%$ vanadium), the temperature for the end of martensitic transformation $\left(M_{f}\right)$ is below room temperature. As a result, the room temperature microstructure after fast cooling always contains some retained $\beta$-phase with $\alpha^{\prime}$ martensite [5]. The formation of fusion weld microstructures is fairly well understood these days for titanium alloys, especially for similar Ti-6Al-4V weld [10]. Fusion welding processes, such as laser and electron beam welding in dissimilar titanium alloys, have still not been explored in detail.

Conventional welding methods, such as gas tungsten arc welding (GTAW), can be used to join Ti alloys, but the high heat input during arc welding can significantly reduce ductility and formability, partially due to grain coarsening in the fusion zone (FZ) and heat-affected zones (HAZs) [11]. However, high cooling rate associated with high energy density in the laser welding process refines the microstructures and generally produces narrow FZ and HAZs, thereby increasing ductility and reducing distortion [11]. Solid-state laser welding technologies, such as neodymium-doped yttrium aluminum garnet (Nd:YAG) and ytterbium-doped yttrium aluminum garnet (Yb:YAG), have been adopted by the aerospace industry due to their rapid and accurate method of joining metal sheets with minimal heat input and relatively lower thermal distortions [12]. In terms of performance, power scalability, reliability, efficiency, and operating lifetime, Yb:YAG is superior to Nd:YAG or other solid-state lasers. In addition, Yb:YAG is relatively compact and robust and provides better beam quality compared to other solid-state lasers [13]. One of the important factors that can affect the weld quality of laser-welded joint is the keyhole stability, which is generally achieved at high laser power and welding speed $[14,15]$. Therefore, ytterbium-doped fiber laser that can produce deep penetrating joints at high welding speeds is a suitable choice to weld both similar and dissimilar metals sheets [16].

Fiber laser weldability of various similar titanium alloys has been reported in the literature [6,17-22]. Li et al. [6] studied the mechanical properties of Yb:YAG laser-welded CP-Ti joints and reported that the tensile failures in the welded joints took place in the base metal (BM) despite having a mixture of coarsened and elongated $\alpha$ grains in the HAZ and FZ. Köse and Karaca [17] reported that increasing the heat input in Nd:YAG fiber laser welding of Ti-64 can lead to grain coarsening in the FZ, resulting in a reduction of tensile strength, impact toughness, and hardness. Ahn et al. [18] investigated the effect of laser power, welding speed, and beam focal position on fiber laser weldability of similar Ti-64 and reported that low laser power or high welding speed (lower heat input) led to finer martensite and prior $\beta$ grains in the FZ.

Although dissimilar joining of materials is of technological interest in various industrial applications to lightweight the structure and often to reduce expenses, there is lack of enough research on dissimilar laser-welded Ti alloys [23-25]. Analysis and comparison of the microstructure and mechanical properties of dissimilar laser-welded Ti-22Al-25Nb/TA15 joints under single- and dual-laser beam by Shen et al. [23] showed that the hardness and average tensile strength of the weld increased when using dual-laser instead of single-laser beam. Hsieh et al. [24] studied the effect of post weld heat treatment on the microstructure and mechanical properties of $\mathrm{CO}_{2}$ laser-welded dissimilar Ti-15V-3Cr-3Al-3Sn (Ti-153) to Ti-64 and reported that the low microindentation hardness of as-welded FZ in dissimilar Ti-64/Ti-153 could be significantly increased by distinct post weld heat treatments. Froend et al. [25] investigated the shape and morphology of welded seam as well as the presence and form of defects in dissimilar T-joints between CP-Ti and Ti-64 welded by ytterbium fiber laser. They identified 13 process parameters, including laser power, welding speed, gas shield, 
and angle of laser, which had strong influences on the weld quality. This is the only research paper published on the dissimilar weldability of CP-Ti and Ti-64 and is mostly focused on the seam geometry, weld quality, distortion, and defects. Therefore, the primary objective of this research work was to study the feasibility of autogenously welding (similar and dissimilar) CP-Ti and Ti-64 alloys using ytterbium fiber laser. Weld quality of similar and dissimilar butt joints were studied by analyzing the microstructure, defects, and mechanical properties.

\section{Materials and Methods}

In this project, Grade 1 commercially pure titanium (CP-Ti) and Grade $5 \mathrm{Ti}-6 \mathrm{Al}-4 \mathrm{~V}$ (Ti-64) sheets with $3 \mathrm{~mm}$ thicknesses were welded. The composition of the alloys are shown in Table 1 . The dimension of the plates was approximately $100 \mathrm{~mm} \times 50 \mathrm{~mm} \times 3 \mathrm{~mm}$, and the plates were welded along the length.

Table 1. Nominal compositions of the alloys.

\begin{tabular}{ccccccccc}
\hline Alloy & Al (\%) & V (\%) & Fe (\%) & O (\%) & $\mathbf{C ~ ( \% )}$ & H (\%) & N (\%) & Ti (\%) \\
\hline Ti-64 & 6 & 4 & 0.25 & 0.2 & - & - & - & balance \\
CP-Ti & - & - & 0.2 & 0.18 & 0.1 & 0.015 & 0.03 & balance \\
\hline
\end{tabular}

Sheets were welded both similarly and dissimilarly, meaning three kinds of joints were prepared: CP-Ti/CP-Ti similar, Ti-64/Ti-64 similar, and CP-Ti/Ti-64 dissimilar. The autogenous butt welding was performed using an IPG Photonics YLS-15000 $15 \mathrm{~kW}$ fiber laser (Yb:YAG) welding machine (Solution Novika, La Pocatière, QC, Canada). In fiber laser welding, heat input (HI) can be calculated using Equation (1) [8]:

$$
\mathrm{HI}\left(\frac{\mathrm{J}}{\mathrm{mm}}\right)=\eta \frac{\text { Laser Power }(\mathrm{W})}{\text { Welding Speed }\left(\frac{\mathrm{mm}}{\mathrm{S}}\right)}
$$

where $\eta$ is the efficiency of the fiber laser welding process, which is considered as $80 \%$ based on company report. Prior to welding, the plates were ground to make the surfaces as flat as possible and finally cleaned with ethanol to remove dirt. Argon was used as shielding gas ( 1 bar) at both top and bottom sides of the weld. The laser spot diameter was $0.48 \mathrm{~mm}$ (optical fiber diameter: $0.2 \mathrm{~mm}$ ) and a defocusing distance of $-1 \mathrm{~mm}$ (laser beam focal point was $1 \mathrm{~mm}$ below the surface of the plates) was used. The welding parameters are reported in Table 2. The weld parameters were chosen in such a way that the heat input remained constant at $85 \mathrm{~J} / \mathrm{mm}$. From each joint, a strip perpendicular to the weld length was cut and mounted for microstructural characterization of the weld cross section. All samples were ground with 120, 240, 400, 600, 800, and 1200 grid SiC papers and polished with 0.3 and $0.05 \mu \mathrm{m}$ alumina suspension. All polished samples were etched with Kroll's reagent ( $2 \mathrm{~mL} \mathrm{HF}+$ $6 \mathrm{~mL} \mathrm{HNO}_{3}+100 \mathrm{~mL} \mathrm{H}_{2} \mathrm{O}$ ) for 7 to $10 \mathrm{~s}$ based on the point of interest. Optical images were taken by an AmScope inverted metallurgical optical microscope (AmScope, Irvine, CA, USA) and analyzed for quantitative measurements by ImageJ software (1.52p, NIH, Bethesda, MD, USA).

Table 2. Welding parameters.

\begin{tabular}{cccc}
\hline Joint & Laser Power $\mathbf{( k W )}$ & Welding Speed $(\mathbf{m} / \mathbf{m i n})$ & Heat Input $(\mathbf{J} / \mathbf{m m})$ \\
\hline CP-Ti/CP-Ti & 3 & 1.69 & 85 \\
Ti-64/Ti-64 & 3 & 1.69 & 85 \\
CP-Ti/Ti-64 & 3 & 1.69 & 85 \\
CP-Ti/CP-Ti & 4 & 2.25 & 85 \\
Ti-64/Ti-64 & 4 & 2.25 & 85 \\
CP-Ti/Ti-64 & 4 & 2.25 & 85 \\
\hline
\end{tabular}

From each joint, three tensile samples were cut by an electrical discharge machining (EDM, Sparx EDM, Ottawa, ON, Canada) based on the ASTM-E8M standard [26]. Three tensile tests were performed 
for each joint at room temperature at a constant crosshead speed of $2 \mathrm{~mm} / \mathrm{min}$ using a $100 \mathrm{kN}$ MTS machine (Instron, Norwood, MA, USA). The Vickers microindentation hardness was measured using Buehler-MicroMet 6030 hardness tester (Buehler, Lake Bluff, IL, USA) with $500 \mathrm{~g}$ load and $15 \mathrm{~s}$ of dwell time with a space of $0.2 \mathrm{~mm}$ between two indentations according to ASTM E384-89 standards [27]. The Zeiss Gemini SEM 500 (Zeiss, Oberkochen, Germany) was used for fractography of the tensile fracture surfaces.

\section{Results and Discussion}

\subsection{Macro- and Microstructure Evaluation}

The macrostructure for all the similar and dissimilar joints with two different laser powers are shown in Figure 1. Fully penetrated joints were obtained with all the parameters used in this study for both similar and dissimilar welds.

\section{CP-Ti / CP-Ti}

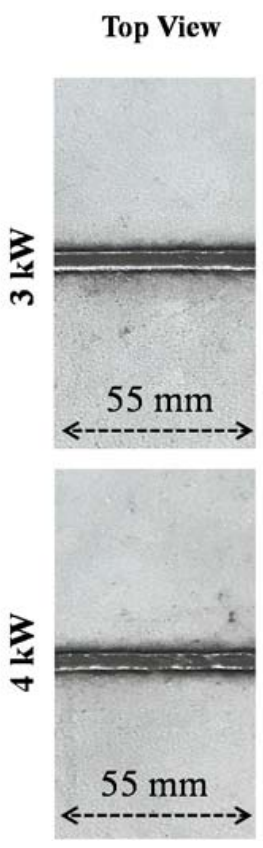

Back View
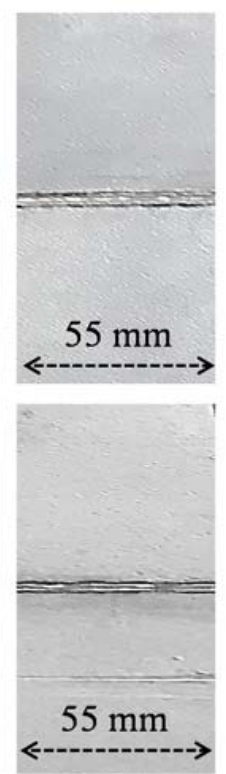

Ti-64 / Ti-64

Top View Back View
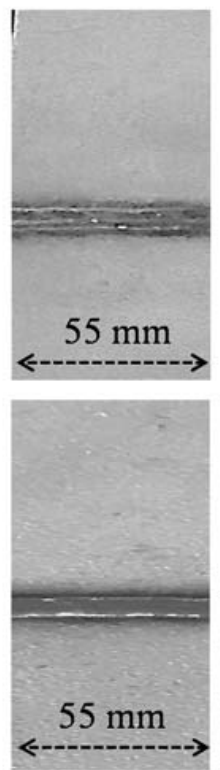
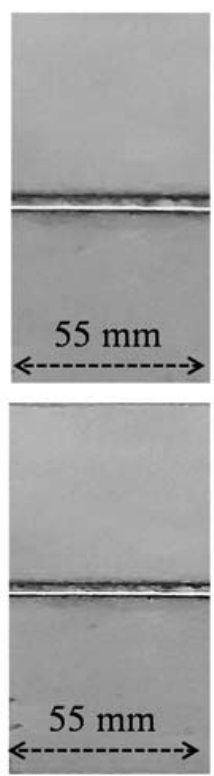

CP-Ti / Ti-64

Top View Back View
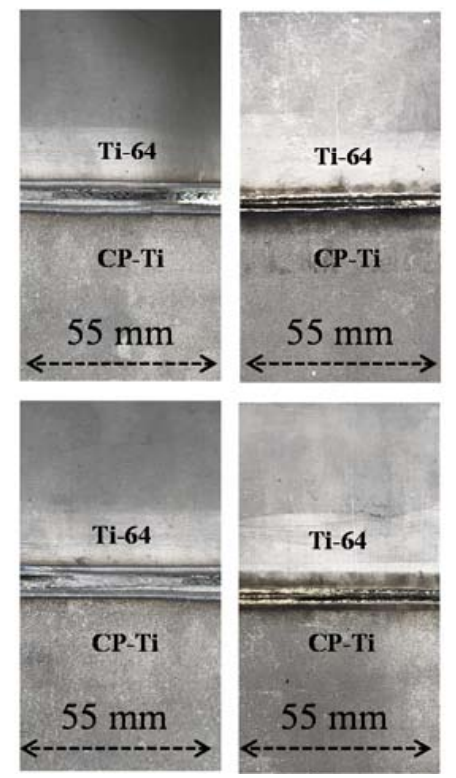

Figure 1. Macrostructures for all the joints.

Figure 2 shows the microstructures of the BM for CP-Ti and Ti-64. The microstructure of the CP-Ti $\mathrm{BM}$ consisted of equiaxed $\alpha$ grains with an average grain size of $27 \mu \mathrm{m}$ and a small yet noticeable amount of $\beta$-phase around the grain boundaries and along the rolling direction. The presence of $\beta$-phase in CP-Ti is linked to the percentage of cold work during manufacturing [28]. The Ti-64 BM microstructure corresponded to a typical mill-annealed condition, where the $\beta$-phase was more or less evenly distributed in the $\alpha$ matrix. In both images, the light phase corresponds to $\alpha$, and the dark phase corresponds to $\beta$. Based on image analysis, CP-Ti and Ti-64 consisted of approximately 3\% and $12 \%$ of $\beta$-phase, respectively.

Figure 3 shows the microstructures of the HAZ and FZ in two similar joints welded by 3 and $4 \mathrm{~kW}$ laser powers. In similar CP-Ti joint, grain size in the HAZ increased slightly at higher laser power due to grain growth associated with the relatively more heat from the FZ during solidification. In the FZ, the average $\alpha$ grain size decreased by increasing the laser power and welding speed from 490 to $251 \mu \mathrm{m}$, even though the heat input was constant. At higher laser power, some needle-shaped $\beta$-phase was also observed (Figure $4 \mathrm{~A}$ ). The cooling rate increased by increasing the laser power and welding speed, which meant there was less time for grain growth, resulting in smaller grain size in the FZ [14]. 


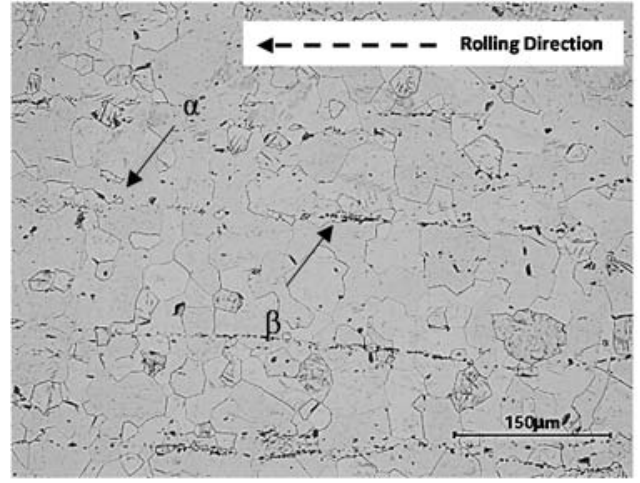

(A)

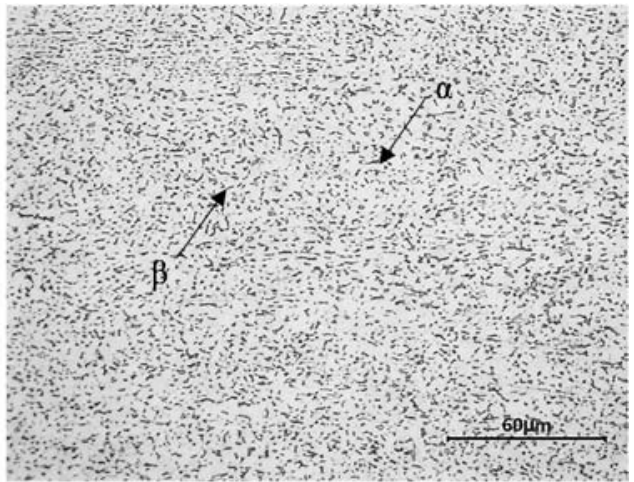

(B)

Figure 2. Base metal (BM) microstructures for (A) CP-Ti and (B) Ti-64. It should be noted that the lower magnification image is shown for $\mathrm{CP}-\mathrm{Ti}$ to accommodate large grains.

$3 \mathrm{~kW}-1.69 \mathrm{~m} / \mathrm{min}$
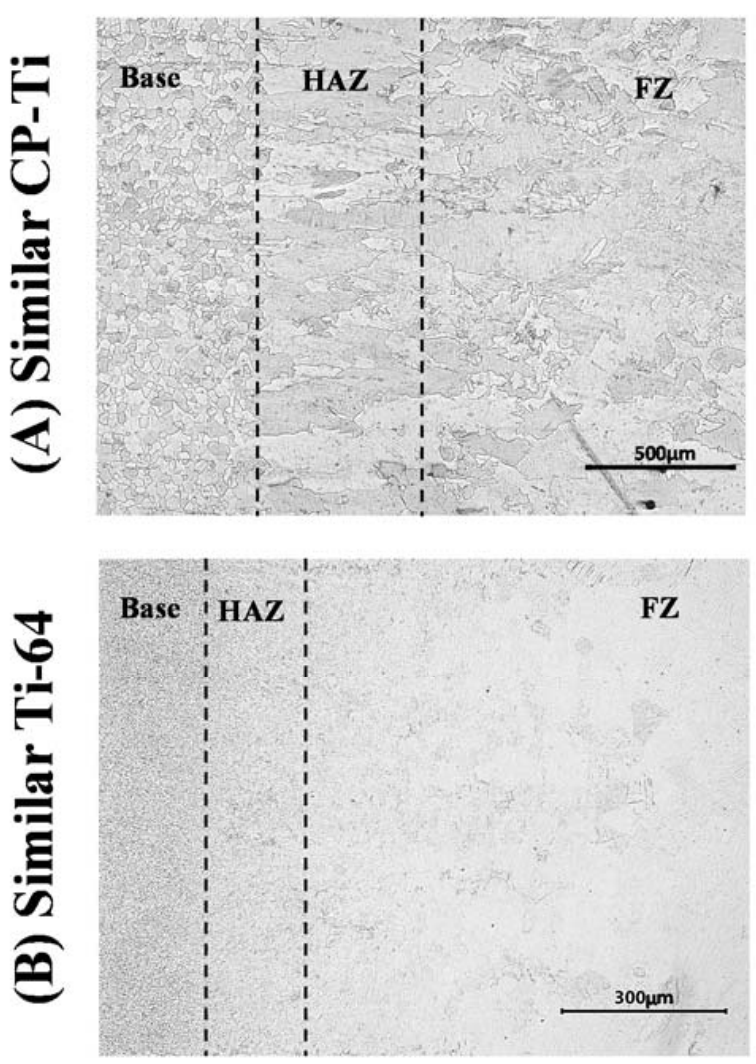

$4 \mathrm{~kW}-2.25 \mathrm{~m} / \mathrm{min}$
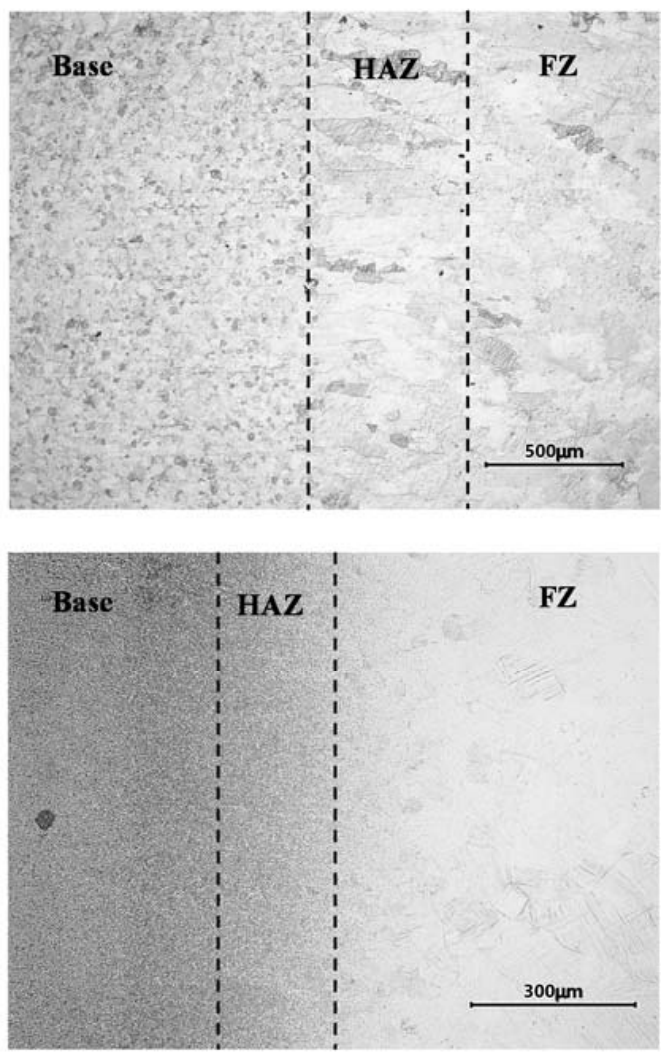

Figure 3. Heat-affected zone (HAZ) and fusion zone (FZ) for similar (A) CP-Ti and (B) Ti-64 joints welded by 3 and $4 \mathrm{~kW}$ laser power.

In similar Ti-64 joint, the FZ consisted of columnar prior beta grains that grew epitaxially in a direction opposite to the heat flow. Within the prior beta grains, $\alpha^{\prime}$ martensite was the predominant phase due to rapid cooling associated with laser welding. $\alpha^{\prime}$ martensite formed mainly due to diffusionless transformation from the high-temperature $\beta$-phase. In the HAZ, the microstructure varied depending on the thermal conditions. Close to the FZ, the temperature was above the $\beta$-transus, and the microstructure was mainly $\alpha^{\prime}$ martensite and some primary $\alpha$ and remnant $\beta$. Moving further away from FZ, the microstructure gradually changed to $\alpha+\beta$ due to a decrease in temperature below 
the $\beta$-transus. There were no observable differences found in the FZ and HAZ microstructures for Ti-64 for the two studied laser powers (Figure 4B).

$3 \mathrm{~kW}-1.69 \mathrm{~m} / \mathrm{min}$
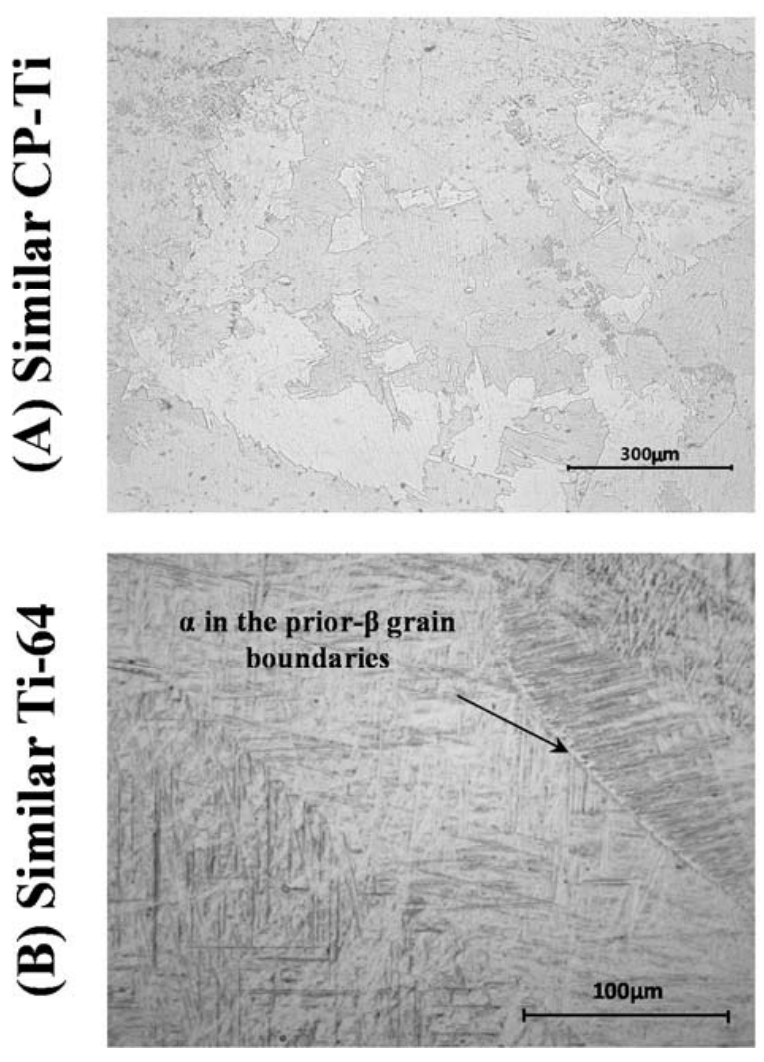

$4 \mathrm{~kW}-2.25 \mathrm{~m} / \mathrm{min}$
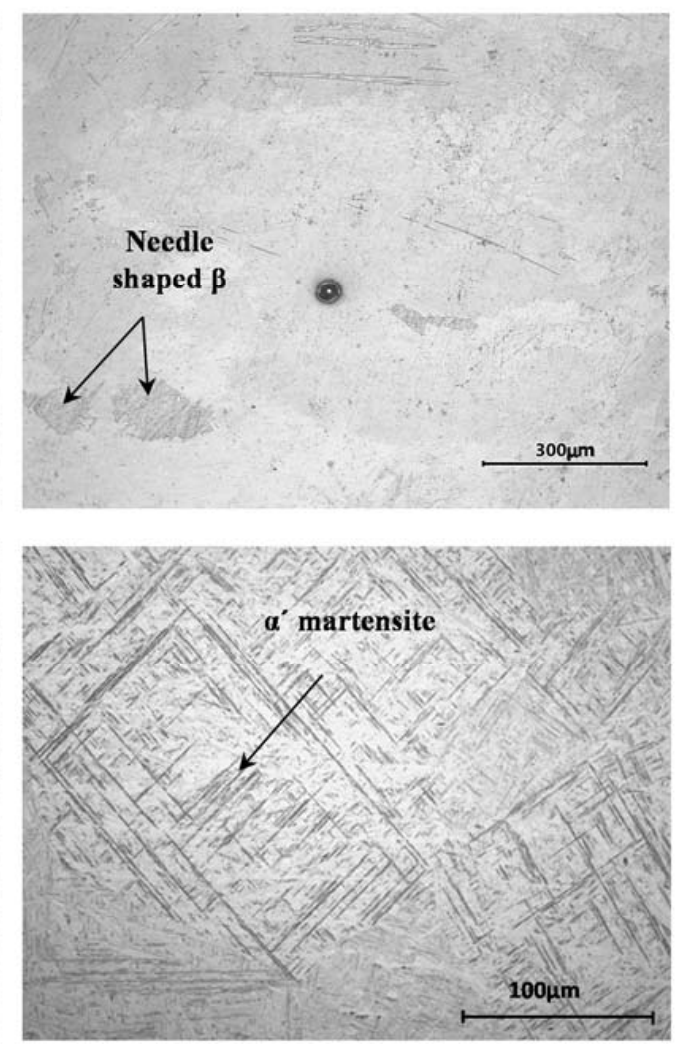

Figure 4. FZ for similar (A) CP-Ti and (B) Ti-64 joints welded by 3 and $4 \mathrm{~kW}$ laser power. It should be noted that images with lower magnification are shown for CP-Ti to accommodate large alpha grains.

Figure 5 shows the HAZ and FZ microstructures for the 3 and $4 \mathrm{~kW}$ dissimilar joints. In the HAZ, the microstructures gradually changed from FZ to BM microstructure in accordance with the similar joints mentioned earlier. However, clear interfaces were observed between the HAZ and the FZ in both the CP-Ti and Ti-64 sides. The interface between the HAZ and Ti-64 FZ was observed where $\alpha^{\prime}$ martensitic transformation was prominent in the FZ. However, the interface at the CP-Ti side was visible due to the presence of some prior $\beta$-phases at the interface. Although the Ti-64 HAZ showed a martensitic structure, no evidence of martensite was observed in the CP-Ti HAZ. The size of $\alpha^{\prime}$ martensite in the dissimilar FZ was shorter and thicker compared to the similar Ti-64 joints. This can be explained by the fact that the thermal conductivity of CP-Ti is less than Ti-64, especially when the temperature is more than $300{ }^{\circ} \mathrm{C}$ [29]. Therefore, in dissimilar joint, the heat dissipation rate in CP-Ti would be lower than the Ti-64 side, letting most of the heat to flow through the Ti-64 side. In addition, the diffusion of $\mathrm{Al}$ and $\mathrm{V}$ during dissimilar joining might have contributed to the evolved interfacial microstructure. This probably gave enough time for $\alpha^{\prime}$ martensite to become thicker in the Ti-64 side.

Two major types of defects were observed in the joints: FZ porosity and underfill. Generally speaking, the average size and amount of porosity decreased for higher laser power, mainly due to the variation in power density. High power density (higher laser power and welding speed) is an important factor for achieving and maintaining the keyhole mode of welding [14]. Therefore, during the $4 \mathrm{~kW}$ laser welding, relatively more stable keyhole was formed, resulting in less and finer porosity compared to the $3 \mathrm{~kW}$ laser power. Underfill was another kind of defect that was observed more or less for all the joints, but it was relatively higher for the specimens welded with $4 \mathrm{~kW}$ laser power. 
In addition, Ti-64 similar joints showed the highest underfill depth among all the joints. Underfill is mainly formed due to the evaporation and expulsion of liquid metal and is more severe during high power density when more molten metal is evaporated from the FZ, losing the necessary amount of metal to fill the whole area during solidification [14]. For dissimilar joints, like the similar joints, porosities were observed mostly at the bottom of the welds, which indicates that the instability of the keyhole was the main mechanism of porosity formation. Volume percentage of porosities were calculated from three different cross sections and were found to be $2.37 \%$ and $0.32 \%$ for 3 and $4 \mathrm{~kW}$, respectively, which indicates that the keyhole was much more stable at higher laser power despite the fact that the heat input was constant in both cases.

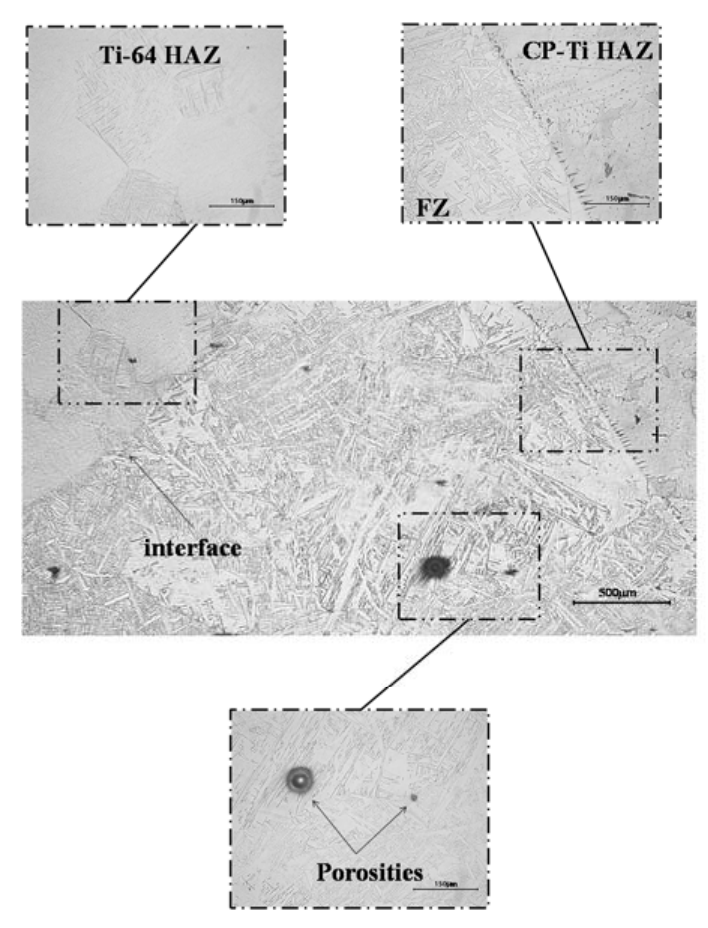

(A)

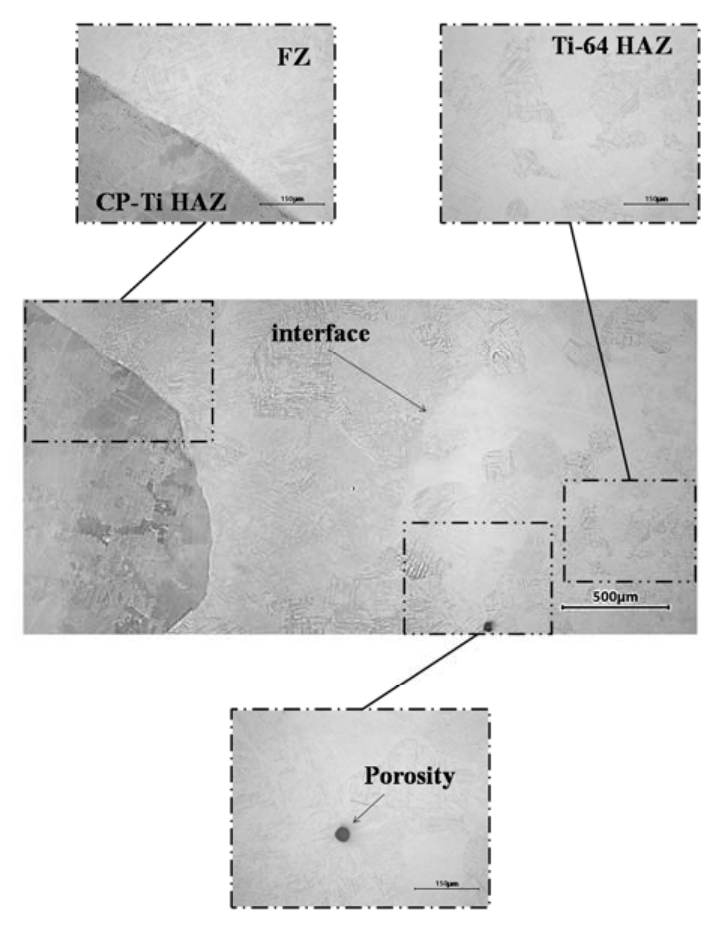

(B)

Figure 5. FZ of dissimilar joint for CP-Ti/Ti-64 welded by (A) $3 \mathrm{~kW}$ and (B) $4 \mathrm{~kW}$ laser power.

\subsection{Tensile Properties}

Figure 6 shows the stress-strain curves for both similar and dissimilar joints welded with 3 and $4 \mathrm{~kW}$ laser powers. The mechanical properties obtained from these curves are shown in Table 3.

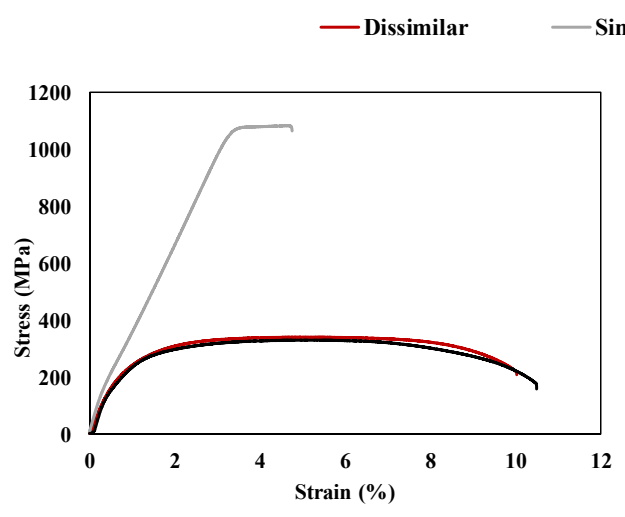

(A)

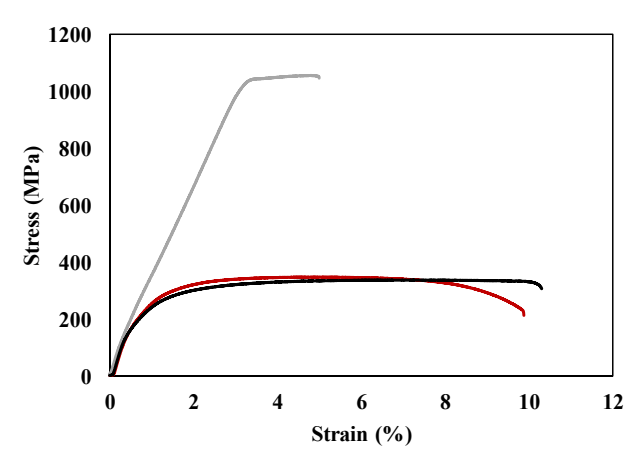

(B)

Figure 6. Stress-strain curves for joints welded by (A) $3 \mathrm{~kW}$ and (B) $4 \mathrm{~kW}$ laser power. 
Table 3. Average mechanical properties for all the welded joints.

\begin{tabular}{|c|c|c|c|c|}
\hline Type of Joint & Tensile Strength (MPa) & Yield Strength (MPa) & Elongation (\%) & Fracture Location \\
\hline \multicolumn{5}{|c|}{$3 \mathrm{~kW}$} \\
\hline Similar CP-Ti & $323 \pm 15$ & $188 \pm 25$ & $9.99 \pm 0.55$ & $\mathrm{BM}$ \\
\hline Similar Ti-64 & $1112 \pm 25$ & $1095 \pm 20$ & $5.47 \pm 1.48$ & $\mathrm{FZ}$ \\
\hline Dissimilar & $338 \pm 8$ & $198 \pm 15$ & $9.59 \pm 0.62$ & CP-Ti BM \\
\hline \multicolumn{5}{|c|}{$4 \mathrm{~kW}$} \\
\hline Similar CP-Ti & $334 \pm 9$ & $188 \pm 8$ & $10.16 \pm 2.72$ & $\mathrm{BM}$ \\
\hline Similar Ti-64 & $1003 \pm 13$ & $989 \pm 6$ & $5.09 \pm 1.27$ & $\mathrm{FZ}$ \\
\hline Dissimilar & $345 \pm 2$ & $213 \pm 11$ & $9.44 \pm 0.58$ & CP-Ti BM \\
\hline
\end{tabular}

Figure 7 shows the effect of welding parameters on the mechanical properties of all the similar and dissimilar joints. In similar CP-Ti and dissimilar joints, the average tensile strengths were 334 and $345 \mathrm{MPa}$ and the fracture strains were $10 \%$ and $9.6 \%$, respectively. The tensile mechanical properties of these two joints were comparable to that of CP-Ti base metal [30]. This was expected as all the joints of these two categories failed in the CP-Ti BM during tensile testing. Therefore, the mechanical properties were determined by the weakest section of the joints, regardless of the microstructures of the FZs and HAZs. In similar Ti-64 joints, coupons failed at an average elongation of 5.5\% with an average tensile strength of $1082 \mathrm{MPa}$, therefore showing the highest strength and the lowest elongation compared to the other joints. All of the 3 and $4 \mathrm{~kW}$ Ti- 64 similar joints failed in the FZ during tensile testing. This is partially due to the maximum underfill defect that has been observed for this kind of joint. For similar CP-Ti and dissimilar joints, the maximum underfill depth was found to be on average $3 \%$ of the sheet thickness, whereas for similar Ti-64 joints, the average maximum underfill depth was found to be approximately 9\%. According to the American Welding Society Standard (AWS D17.1) [31], the maximum tolerable underfill depth for a fusion welded titanium sheet can be 7\% for aerospace application, which is quite strict compared to the existing $9 \%$. Although the tensile crack was initiated at the underfill defect due to the stress concentration, the propagation was determined by the amount of porosity in the FZ. Despite having strong martensite, the amount of porosity was significantly higher in the FZ. Therefore, instead of propagating through the relatively weaker HAZ, the crack grew through the FZ, where the failure ultimately took place. Typical fracture surfaces from the cup and cone shape configurations are shown in Figure 8. The presence of dimples in all three types of joints indicate ductile failures; however, similar Ti-64 fracture surface (Figure 8B) revealed a cluster of pores at the bottom of the FZ, which can be explained by the collapse of the keyhole [14]. The presence of a cluster of porosities in similar Ti- 64 joint weakened the FZ by decreasing the weld cross-sectional area and increasing the local stress concentration.

As mentioned before, the failure location for both similar CP-Ti and dissimilar joints were the same, i.e., the CP-Ti BM. Hence, changing the laser power or welding speeds would not affect the tensile mechanical properties of these two joints. The FZ and HAZ remained stronger, indicating more than $100 \%$ joint efficiency. However, in similar Ti-64 joints, the yield and tensile strength were found to be approximately $11 \%$ lower for $4 \mathrm{~kW}$ laser power compared to $3 \mathrm{~kW}$ laser power. The average elongation was also $7 \%$ lower with $4 \mathrm{~kW}$ laser power. Despite different laser power and welding speed, the heat input was constant and therefore the differences were not expected. It is widely believed that the microstructure and mechanical properties are mostly controlled by the heat input rather than individual welding parameters [32]. Although the FZ microstructures were similar for both 3 and $4 \mathrm{~kW}$ laser powers, the underfill defect was higher for $4 \mathrm{~kW}$ laser power due to increased power density, which generated higher cooling rate and higher expulsion of liquid metal. The amount of porosity for both laser powers remained high enough to let the crack propagate through the FZ. The higher underfill depth was considered to be the main reason for the reduced strength and ductility of the $4 \mathrm{~kW}$ laser power joint. 

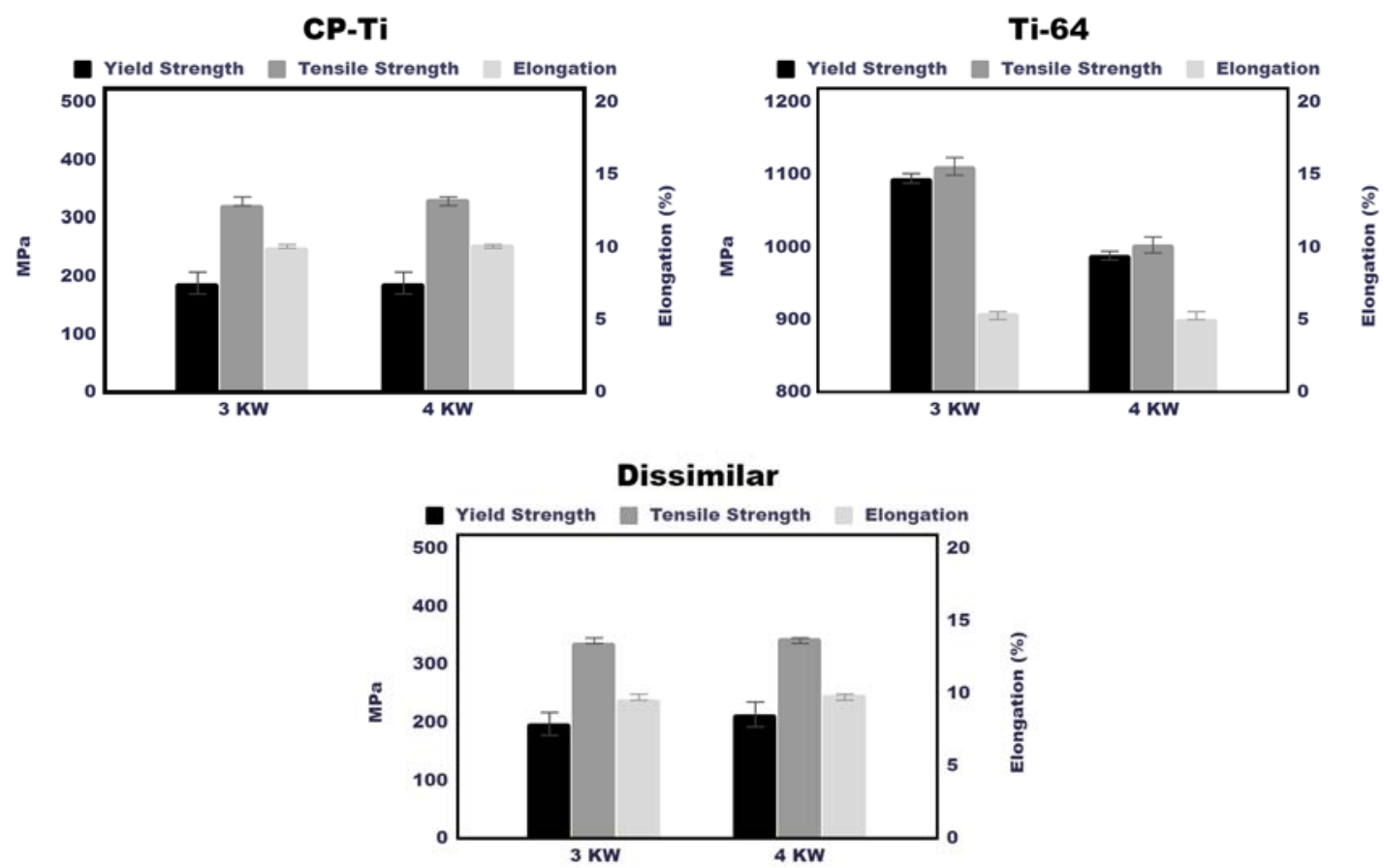

Figure 7. Comparison of mechanical properties for joints welded by 3 and $4 \mathrm{~kW}$ laser power.

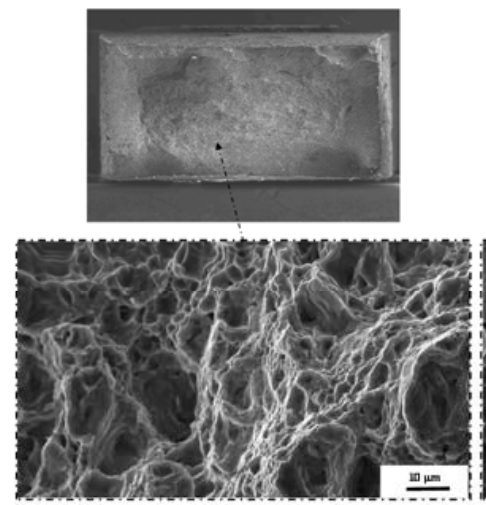

(A)
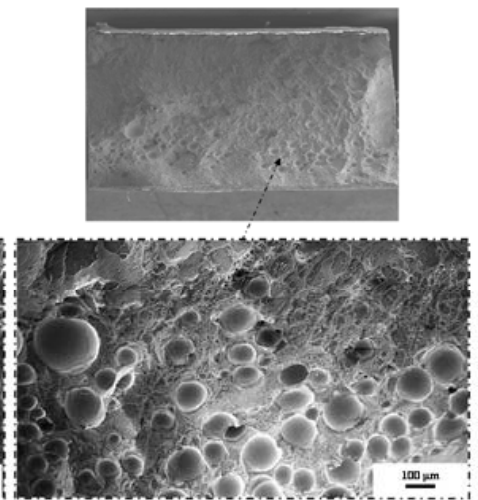

(B)
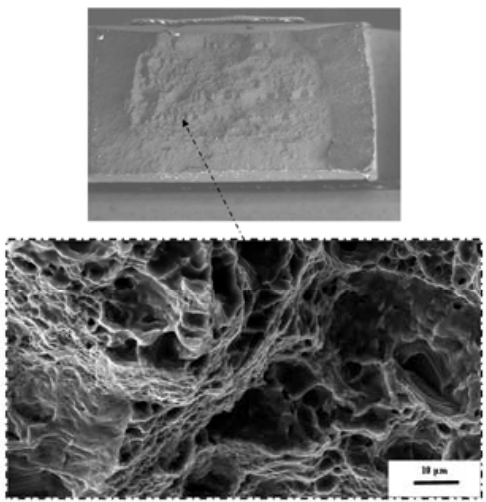

(C)

Figure 8. Typical SEM fractography of fractured tensile specimens. (A) CP-Ti similar, (B) Ti-64 similar, and $(\mathbf{C})$ dissimilar.

\subsection{Microindentation Hardness}

The Vickers microindentation hardness profile for similar and dissimilar joints are shown in Figure 9. The microhardness profiles at two laser powers for both similar joints show very comparable data, therefore, only $3 \mathrm{~kW}$ is reported here. The average FZ hardness of CP-Ti and Ti-64 similar joints were $146 \pm 7$ and $341 \pm 8 \mathrm{HV}$, respectively, roughly $22-25 \%$ higher than the corresponding BM hardness. In similar CP-Ti joint, the difference in average hardness between the FZ and the BM can be explained by the texture variation in these two areas. In general, the average hardness increases by increasing the length of low-angle boundaries (LABs) and simultaneously decreasing the length of high-angle boundaries (HABs) [33]. In the BM, the manufacturing process leads to recrystallization and reduction in the length of LABs. However, in the FZ, due to rapid cooling, there is a remarkable increase in the length of LABs and decrease in the length of HABs, which causes higher average hardness in the FZ compared to the BM. The average FZ hardness for similar Ti-64 increased due to the presence of $\alpha^{\prime}$ martensite, which exhibited high strength and hardness but low ductility and toughness. 


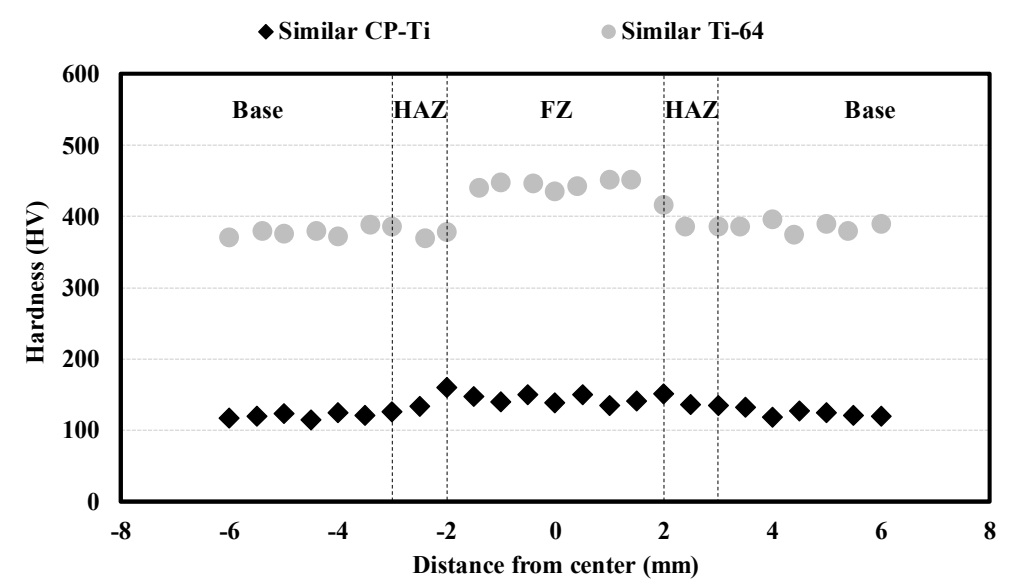

(A)

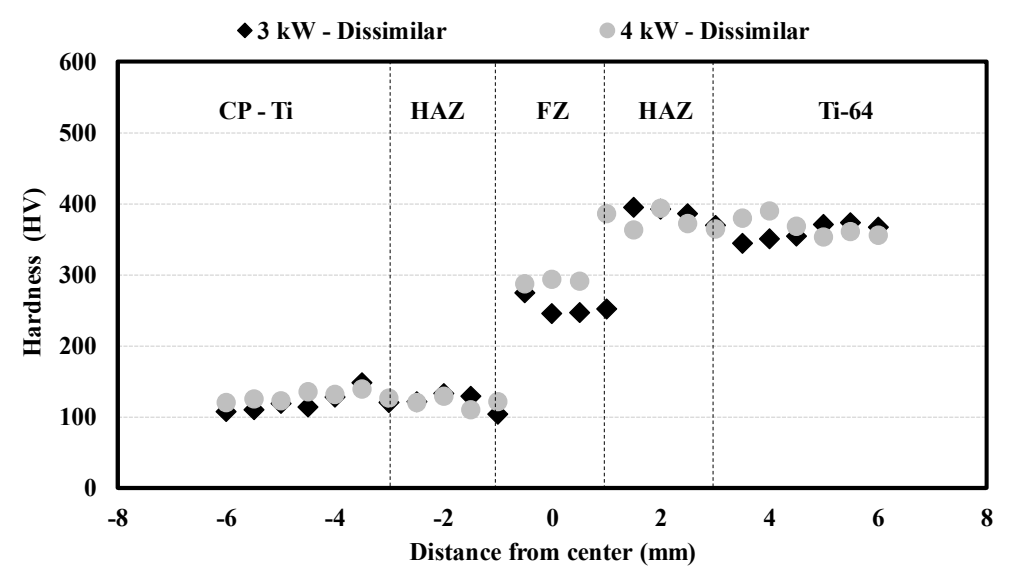

(B)

Figure 9. Hardness distribution profile (base to base) for (A) similar $3 \mathrm{~kW}$ and (B) 3 and $4 \mathrm{~kW}$ dissimilar joints.

Microindentation hardness for 3 and $4 \mathrm{~kW}$ dissimilar joints also showed a similar trend. The Ti-64 base metal and HAZ showed the maximum hardness values. Compared to BMs, FZ hardness showed values between Ti-64 and CP-Ti similar welds. The average FZ hardness for 3 and $4 \mathrm{~kW}$ dissimilar joints were $255 \pm 9$ and $290 \pm 4$, respectively. It is quite interesting to note that even though the heat input was constant, the average FZ hardness for $4 \mathrm{~kW}$ laser power was about $14 \%$ higher compared to that for $3 \mathrm{~kW}$. This may be related to the formation of finer $\alpha^{\prime}$ martensite due to the higher cooling rate associated with increasing laser power and welding speed.

\section{Conclusions}

Similar and dissimilar butt joints between CP-Ti and Ti-64 were ytterbium fiber laser welded using various welding speeds and laser powers in such a way that the heat input remained constant. Weld quality was investigated by studying the microstructures, defects, and mechanical properties. The following conclusions could be made from this work.

In dissimilar joints, a clear interface was observed between the HAZ and the FZ in both the CP-Ti and Ti-64 sides, which can be explained by sudden changes in the prominent microstructure. Martensite formed in the FZs of both similar Ti-64 joint and dissimilar joints. Compared to the FZ in similar Ti-64 joints, $\alpha^{\prime}$ martensite formed in the dissimilar FZ was found to be shorter and thicker.

Porosity and underfill were the only observed defects in all the joints. Defects did not affect the mechanical integrity of similar CP-Ti and dissimilar joints. Formation of martensite in dissimilar joint did not make the weld stronger as the coupons failed during tensile testing in the CP-Ti base metal. 
Despite having the same heat input, laser power and welding speed had a significant effect on mechanical properties of similar Ti-64 joints. Higher laser power created maximum underfill depth beyond the acceptable limit for aerospace application, which reduced the weld integrity significantly.

In dissimilar joints, $\mathrm{FZ}$ average hardness increased by $14 \%$ by increasing laser power and welding speed despite the same heat input. This implied that the mechanical properties of the weld fusion zones were not completely governed by the heat input but were instead a function of each individual welding parameter, which influenced the weld properties individually.

Author Contributions: Formal analysis, A.A.; funding acquisition, A.S.K.; investigation, A.A., A.S.A.H., and A.S.K.; methodology, A.A. and A.S.K.; project administration, A.A.; resources, A.S.K.; software, A.A.; supervision, A.S.K.; writing-original draft, A.A. and A.S.A.H.; writing-review and editing, A.A., A.S.A.H., and A.S.K. All authors have read and agreed to the published version of the manuscript.

Funding: The authors appreciate the financial support from the Natural Sciences and Engineering Research Council of Canada (NSERC).

Conflicts of Interest: The authors declare no conflict of interest.

\section{References}

1. Hsieh, C.; Chu, C.; Shiue, R.; Tsay, L. The effect of post-weld heat treatment on the notched tensile fracture of Ti-6Al-4V to Ti-6Al-6V-2Sn dissimilar laser welds. Mater. Des. 2014, 59, 227-232. [CrossRef]

2. Boyer, R.R. An overview on the use of titanium in the aerospace industry. Mater. Sci. Eng. A 1996, 213, 103-114. [CrossRef]

3. Vyskoč, M.; Dománková, M.; Sahul, M.; Vyskočová, M. Effect of shielding gas on the properties of CP titanium Grade 2 laser weld joints. Kovove Mater. 2019, 57, 247-265. [CrossRef]

4. Warwick, J.L.; Jones, N.G.; Bantounas, I.; Preuss, M.; Dye, D. In situ observation of texture and microstructure evolution during rolling and globularization of Ti-6Al-4V. Acta Mater. 2013, 61, 1603-1615. [CrossRef]

5. Joshi, V.A. Titanium Alloys: An Atlas of Structures and Fracture Features; CRC Press: Boca Raton, FL, USA, 2006.

6. Li, R.; Zhang, F.; Sun, T.; Liu, B.; Chen, S.; Tian, Y. Investigation of strengthening mechanism of commercially pure titanium joints fabricated by autogenously laser beam welding and laser-MIG hybrid welding processes. Int. J. Adv. Manuf. Technol. 2019, 101, 377-389. [CrossRef]

7. Peters, M.; Kumpfert, J.; Ward, C.H.; Leyens, C. Titanium alloys for aerospace applications. Adv. Eng. Mater. 2003, 5, 419-427. [CrossRef]

8. Kabir, A.S.H.; Cao, X.; Gholipour, J.; Wanjara, P.; Cuddy, J.; Birur, A.; Medraj, M. Effect of postweld heat treatment on microstructure, hardness, and tensile properties of laser-welded Ti-6Al-4V. Metall. Mater. Trans. A 2012, 43, 4171-4184. [CrossRef]

9. Ahmed, T.; Rack, H. Phase transformations during cooling in $\alpha+\beta$ titanium alloys. Mater. Sci. Eng. A 1998, 243, 206-211. [CrossRef]

10. Dhinakaran, V.; Shriragav, S.; Fahmidha, A.F.Y.; Ravichandran, M. A review on the categorization of the welding process of pure titanium and its characterization. Mater. Today Proc. 2020, in press. [CrossRef]

11. Cui, L.; Bin, L.; Wu, Z.-F.; Qi, X.-Y.; Bing, Y.; Wang, A.-H. Stitch welding of Ti-6Al-4V titanium alloy by fiber laser. Trans. Nonferrous Met. Soc. China 2017, 27, 91-101.

12. Jayanthi, A.; Venkataramanan, K.; Suresh Kumar, K. Laser beam a novel tool for welding: A review. IOSR J. Appl. Phys. 2016, 8, 08-26.

13. Li, C.; Muneharua, K.; Takao, S.; Kouji, H. Fiber laser-GMA hybrid welding of commercially pure titanium. Mater. Des. 2009, 30, 109-114. [CrossRef]

14. Cao, X.; Kabir, A.S.H.; Wanjara, P.; Gholipour, J.; Birur, A.; Cuddy, J.; Medraj, M. Global and local mechanical properties of autogenously laser welded Ti-6Al-4V. Metall. Mater Trans. A 2014, 45, 1258-1272. [CrossRef]

15. Casalino, G.; Mortello, M.; Campanelli, S.L. Ytterbium fiber laser welding of Ti6Al4V alloy. J. Manuf. Process. 2015, 20, 250-256. [CrossRef]

16. Beguin, J.D.; Gazagne, V.; Balcaen, Y.; Alexis, J.; Andrieu, E. Laser Welding of Titanium Alloys with an Yb: YAG Disk Source. Mater. Sci. Forum 2018, 941, 845-850. [CrossRef]

17. Köse, C.; Karaca, E. Robotic Nd: YAG fiber laser welding of Ti-6Al-4V Alloy. Metals 2017, 7, 221. [CrossRef] 
18. Ahn, J.; Chen, L.; Davies, C.; Dear, J. Parametric optimisation and microstructural analysis on high power Yb-fibre laser welding of Ti-6Al-4V. Opt. Lasers Eng. 2016, 86, 156-171. [CrossRef]

19. Ahn, J.; He, E.; Chen, L.; Wimpory, R.; Dear, J.; Davies, C. Prediction and measurement of residual stresses and distortions in fibre laser welded Ti-6Al-4V considering phase transformation. Mater. Des. 2017, 115, 441-457. [CrossRef]

20. Kumar, C.; Das, M.; Paul, C.; Singh, B. Experimental investigation and metallographic characterization of fiber laser beam welding of Ti-6Al-4V alloy using response surface method. Opt. Lasers Eng. 2017, 95, 52-68. [CrossRef]

21. Kumar, C.; Das, M.; Paul, C.P.; Bindra, K. Weld Quality Assessment in Fiber Laser Weldments of Ti-6Al-4V Alloy. J. Mater. Eng. Perform. 2019, 28, 3048-3062. [CrossRef]

22. Ou, W.-M.; Zhan, X.-H.; Wei, Y.-H.; Mi, G.-Y.; Gu, C. Deep penetration welding of Ti-6Al-2Zr-1Mo-1V with a fibre laser. Lasers Eng. 2016, 33, 103-116.

23. Shen, J.; Li, B.; Hu, S.; Zhang, H.; Bu, X. Comparison of single-beam and dual-beam laser welding of Ti-22Al-25Nb/TA15 dissimilar titanium alloys. Opt. Laser Technol. 2017, 93, 118-126. [CrossRef]

24. Hsieh, C.; Shiue, R.; Huang, R.-T.; Tsay, L. The effect of post-weld heat treatment on the microstructure and notched tensile fracture of Ti-15V-3Cr-3Al-3Sn to Ti-6Al-4V dissimilar laser welds. Mater. Sci. Eng. A 2016, 653, 139-146. [CrossRef]

25. Froend, M.; Fomin, F.; Riekehr, S.; Alvarez, P.; Zubiri, F.; Bauer, S.; Klusemann, B.; Kashaev, N. Fiber laser welding of dissimilar titanium (Ti-6Al-4V/cp-Ti) T-joints and their laser forming process for aircraft application. Opt. Laser Technol. 2017, 96, 123-131. [CrossRef]

26. ASTM International. ASTM E8M-04, Standard Test Methods for Tension Testing of Metallic Materials; ASTM Int: West Conshohocken, PA, USA, 2004.

27. Standard, A. E384-89 "Standard Test Method for Microhardness of Materials"; Annual Book of ASTM Standards; ASTM Int: West Conshohocken, PA, USA, 1989; Volume 3.

28. Seward, G.; Celotto, S.; Prior, D.; Wheeler, J.; Pond, R. In situ SEM-EBSD observations of the hcp to bcc phase transformation in commercially pure titanium. Acta Mater. 2004, 52, 821-832. [CrossRef]

29. Chiumenti, M.; Lin, X.; Cervera, M.; Lei, W.; Zheng, Y.; Huang, W. Numerical simulation and experimental calibration of Additive Manufacturing by blown powder technology. Part I: Thermal analysis. Rapid Prototyp. J. 2017, 23, 448-463. [CrossRef]

30. Mouritz, A.P. Introduction to Aerospace Materials; Elsevier: Amsterdam, The Netherlands, 2012.

31. Standard, A. D17. 1: 2001. Specification for Fusion Welding for Aerospace Applications; AWS: Seattle, WA, USA, 2001.

32. Steimbreger, C.; Chapetti, M.D. Fatigue strength assessment of butt-welded joints with undercuts. Int. J. Fatigue 2017, 105, 296-304. [CrossRef]

33. Liu, H.; Nakata, K.; Yamamoto, N.; Liao, J. Mechanical properties and strengthening mechanisms in laser beam welds of pure titanium. Sci. Technol. Weld. Join. 2011, 16, 581-585. [CrossRef]

(C) 2020 by the authors. Licensee MDPI, Basel, Switzerland. This article is an open access article distributed under the terms and conditions of the Creative Commons Attribution (CC BY) license (http://creativecommons.org/licenses/by/4.0/). 